\title{
IN VITRO OSTEOCLASTOGENESIS ON TEXTILE CHITOSAN SCAFFOLDS
}

\author{
C. Heinemann*, S. Heinemann, A. Bernhardt, A. Lode, H. Worch, and T. Hanke \\ Max Bergmann Center of Biomaterials and Institute of Materials Science, Dresden University of Technology, \\ D-01069 Dresden, Germany
}

\begin{abstract}
Textile chitosan fibre scaffolds were evaluated in terms of interaction with osteoclast-like cells, derived from human primary monocytes. Part of the scaffolds was further modified by coating with fibrillar collagen type I in order to make the surface biocompatible. Monocytes were cultured directly on the scaffolds in the presence of macrophage colony stimulating factor (M-CSF) and receptor activator of nuclear factor kappaB ligand (RANKL) for up to 18 days. Confocal laser scanning microscopy (CLSM) as well as scanning electron microscopy (SEM) revealed the formation of multinuclear osteoclast-like cells on both the raw chitosan fibres and the collagen-coated scaffolds. The modified surface supported the osteoclastogenesis. Differentiation towards the osteoclastic lineage was confirmed by the microscopic detection of cathepsin $\mathrm{K}$, tartrate resistant acid phosphatase (TRAP), acidic compartments using 3-(2,4-dinitroanillino)3 '-amino-N-methyldipropylamine (DAMP), immunological detection of TRAP isoform $5 \mathrm{~b}$, and analysis of gene expression of the osteoclastic markers TRAP, cathepsin K, vitronectin receptor, and calcitonin receptor using reverse transcription-polymerase chain reaction (RT-PCR). The feature of the collagen-coated but also of the raw chitosan fibre scaffolds to support attachment and differentiation of human monocytes facilitates cell-induced material resorption - one main requirement for successful bone tissue engineering.
\end{abstract}

Keywords: Textile, chitosan, scaffold, human, monocytes, osteoclasts, osteoclastogenesis, biocompatibility.

*Address for correspondence:

Christiane Heinemann

Max Bergmann Center of Biomaterials and Institute of Materials Science,

Dresden University of Technology

Budapester Str. 27, D-01069 Dresden, Germany

E-mail: christiane.heinemann@tu-dresden.de

\section{Introduction}

For several years the field of bone tissue engineering has been developing promising approaches concerning the socalled third generation biomaterials, which are characterized to support self-healing processes of the tissue concerned (Hench and Polak, 2002). These biomaterials combine good resorptivity with osteoconductivity and osteoinductivity (Salgado et al., 2004). In that context, the polysaccharide chitosan attracted particular attention due to its biocompatibility and cost-effective availability (Di Martino et al., 2005). Chitosan is considered to be a material with good future prospects in regenerative medicine (Kim et al., 2008; Shi et al., 2006). Chitosan is a co-polymer of $\mathrm{N}$-acetylglucosamine and $\mathrm{N}$-glucosamine units and is produced by deacetylation of naturally occurring chitin, which is extracted from shellfish sources (Jayakumar et al., 2008).

In the last two decades, chitosan has become a frequently applied material in regenerative medicine and biomaterials research including orthopaedics, periodontology, drug delivery systems, wound healing applications, and tissue engineering (Khor and Lim, 2003; Kumar et al., 2004; Shi et al., 2006). With respect to its chemical nature chitosan is reminiscent of glycosaminoglycans, components of the extracellular matrix with great importance for bone formation. Similarly, chitosan is able to bind different components of the extracellular matrix as growth factors and cytokines (Huang et al., 2007; Park et al., 2006; Zisch et al., 2003). For tissue engineering that is an interesting feature, because chitosan is able to concentrate added factors in the close vicinity of the scaffold material right on the growth site. In vivo, degradation by hydrolases, mainly lysozyme (1,4- $N$-acetylmuramidase, EC 3.2.1.17) is recognized to break down chitosan, resulting in the formation of non-toxic oligomers (Kohn et al., 1962). Besides lysozyme a wide variety of hydrolases degrade chitosan i.e., chitosanases, cellulase, hemicellulase, amylase, pectinase, lipase and even proteinases, such as pepsin und trypsin (Uragami and Tokura, 2006). Recent studies revealed degradation products of chitosan to be anti-inflammatory as well as to support angiogenesis (Chen et al., 2008; Wang et al., 2008). After implantation chitosan is completely resorbed (Muzzarelli et al., 1994; Taylor et al., 1994). In contrast, degradation products of synthetic polymers are known to cause inflammation at the implantation site by generation of acidic products, and therefore, might be harmful to the surrounding tissue (Athanasiou et al., 1996).

Due to its solubility in dilute acids, chitosan is accessible for various established processing technologies 
and has been used to produce films, gels as well as porous sponge-like scaffolds (Hsu et al., 2004; Manjubala et al., 2008). Besides sponge-like scaffolds made from chitosan, new perspectives in tissue engineering scaffold design were introduced by the availability of processible polymer fibres. Chitosan fibres are produced by the electro-spinning or wet-spinning process (Ohkawa et al., 2004). In the first case, usually chitosan fibre meshes were produced (Slavik et al., 2007; Wawro et al., 2006). So far, these fibre meshes have been sparsely investigated with respect to their applicability as material for bone replacement. Tuzlakoglu et al. reported the coating of chitosan fibre meshes with bioactive calcium phosphate and the subsequent seeding of osteoblast-like cells (Tuzlakoglu et al., 2004; Tuzlakoglu and Reis, 2007). Cunha-Reis et al. investigated the influence of porosity and mesh size on the resorptivity and the behaviour of seeded osteoblast-like cells (CunhaReis et al., 2007). Despite the advantages of fibre scaffold technology for tissue engineering until now only a few studies have reported on the usage of textile structures from pure chitosan. Mostly conventional scaffold materials are slightly modified by the introduction of chitosan fibres (Niekraszewicz et al., 2007; Rochet et al., 2009).

Previously, we described the development of novel scaffold models made of chitosan fibres. Coating with a thin layer of fibrillar collagen type I was applied to make the surface of the scaffolds biocompatible. The excellent suitability of textile chitosan fibre scaffolds for application in bone tissue engineering was demonstrated by cell culture experiments using a murine cell line of osteoblast-like cells (7F2) and human bone marrow stromal cells (hBMSC) (Heinemann et al., 2008; Heinemann et al., 2009). Both cell types revealed fast cell attachment, increase of the cell number over the cultivation period of 28 days, and the expression of the osteogenic phenotype as indicated by the typical pattern of ALP activity, osteocalcin immunostaining, and matrix mineralization.

Consequently, experiments were performed using cells of the hematopoietic origin - monocyte-derived osteoclasts - which play a pivotal role in bone resorption and remodelling in vivo. Monocytes are able to fuse into mature multinuclear osteoclasts after contact with stromal cells or osteoblasts, as well as macrophage colony-stimulating factor (M-CSF) and receptor for activation of nuclear factor kappaB ligand (RANKL), which are expressed by these cells (Suda et al., 1995). In vitro these osteoblastic cytokines can stimulate the fusion and differentiation of monocytes, resulting in the expression of specific markers for active osteoclasts.

Concerning the potential application of the scaffolds for bone tissue engineering it is necessary to create optimal conditions for the development of osteoblasts and on the other hand to ensure that osteoclasts are able to keep their typical functions. Although in tissue engineering it seems very unlikely, that monocytes or osteoclasts will be seeded on the scaffolds prior to implantation, it is important to investigate the interaction of the bone resorbing cells with fibrous scaffold materials, in order to obtain knowledge about the interaction with the engineered material in vivo. This is even more important as only resorption by osteoclasts allows inclusion of a biomaterial into the remodelling process and its full replacement by bone (Schilling et al., 2006). Whereas the interaction between osteoclasts and various calcium phosphate phases (Detsch et al., 2008), calcium phosphate and polymethylmethacrylate (PMMA) cements (Schilling et al., 2004) as well as two-dimensional chitosan films (Jones et al., 2009) have been investigated thoroughly, such studies are still missing in the case of chitosan fibres. The specific morphological conditions of fibres and fabrics are challenging to the monocyte fusion as well as to the necessarily tight interaction between the osteoclast's sealing zone and the substrate. Therefore, in the present study human monocytes were seeded and cultivated on uncoated and collagen-coated chitosan fibre scaffolds for 18 days in the presence of M-CSF and RANKL. Osteoclastic differentiation was investigated by the detection of multinuclearity and differentiation markers using microscopic, biochemical and RT-PCR analysis techniques.

\section{Materials and Methods}

\section{Chitosan fibre scaffolds and collagen coating}

Wet-spun chitosan fibres were provided in the form of a multifilament yarn by Heppe $\mathrm{GmbH}$, Landsberg/Queis, Germany. The raw material is crab chitin, which is deacetylated (DD 90\%) to chitosan of molecular weight between 100,000-200,000. For microscopic analyses the chitosan fibres were tightened between the plastic rings of Minusheet ${ }^{\mathbb{R}}$-Holders (inner diameter $10 \mathrm{~mm}$ ) (Minucells, Bad Abbach, Germany). Stand-alone scaffolds (diameter $10 \mathrm{~mm}$ ) for quantitative biochemical analyses were processed by using the crown knot technique, which merges two chitosan fibres to form a circular threedimensional construct (Heinemann et al., 2008).

Bovine tropocollagen type I (Invitrogen, Carlsbad, CA, USA) was assembled into a fibrillar coating directly on the scaffolds as described previously (Heinemann et al., 2008). In brief, the chitosan scaffolds were soaked in a mixture of tropocollagen solution and physiological buffer solution at $4{ }^{\circ} \mathrm{C}$. Fibrillogenesis was carried out at $37^{\circ} \mathrm{C}$, followed by rinsing and lyophilization. The collagen coating was stabilized by chemical cross-linking using N(3-dimethylaminopropyl)-N'-ethylcarbodiimide (EDC) and N-hydroxysuccinimide (NHS) (both Sigma, Taufkirchen, Germany).

Gamma-irradiation ( $25 \mathrm{kGy}$ ) was used to sterilize the uncoated and collagen-coated chitosan scaffolds before starting the cell culture experiments.

\section{Cell culture}

Human primary monocytes, isolated from buffy coats of healthy adult donors as described, were kindly provided by Prof. Rösen-Wolff and co-workers, University Hospital Dresden, Department of Pediatrics (Domaschke et al., 2006). Cells were cultivated in Minimal Essential Medium ( $\alpha$-modification), supplemented with $7.5 \%$ foetal calf serum (FCS), 7.5\% human A/B serum, 2 mM L-glutamine, 
$10 \mathrm{U} / \mathrm{ml}$ penicillin and $100 \mu \mathrm{g} / \mathrm{ml}$ streptomycin. Medium and all supplements were obtained from Biochrom (Berlin, Germany).

Prior to cell-seeding, scaffolds were placed in 48-wellplates and soaked in cell culture medium for $24 \mathrm{~h}$ in order to prevent floating. After removing the medium, $40 \mu \mathrm{l}$ of monocyte cell suspension (5000 monocytes per $\mu \mathrm{l}$ ) were placed onto each scaffold. Cells were allowed to adhere for $30 \mathrm{~min}$ in the incubator at $37^{\circ} \mathrm{C}$ and $5 \% \mathrm{CO}_{2}$ before filling up the wells with additional medium, which was supplemented with $10 \mathrm{nM}$ dexamethasone (Sigma), 100 nM 1,25-dihydroxy vitamin D3 (Calbiochem, Nottingham, UK), $10 \mathrm{mM} \beta$-glycerophosphate (Sigma), $50 \mathrm{ng} / \mathrm{ml} \mathrm{M-}$ CSF (Biomol, Hamburg, Germany) and $50 \mathrm{ng} / \mathrm{ml} \mathrm{RANKL}$ (Biomol) to induce osteoclastogenesis. The differentiation medium was changed twice weekly.

\section{Microscopy}

Scanning electron microscopy (SEM) was used to characterize the uncoated and collagen-coated chitosan scaffolds before and after cell culture experiments, respectively. Cell-seeded samples were washed with PBS and fixed with $3.7 \%$ formaldehyde. After finishing the confocal laser scanning microscopy (CLSM) experiments, cell-seeded samples were dehydrated, critical-point dried, mounted on stubs, and sputtered with gold. SEM was carried out using a Philips (Eindhoven, The Netherlands) environmental SEM (ESEM) XL 30 in Hi-Vac mode by applying an acceleration voltage of $3 \mathrm{kV}$ and detecting secondary electrons for imaging.

CLSM was applied to evaluate adhesion, multinuclearity, and differentiation of the cells. After washing and fixing, the cells were permeabilized with $0.2 \%$ Triton-X-100 in PBS and blocked with $1 \%$ bovine serum albumin (BSA, Sigma) for $30 \mathrm{~min}$. Cytoskeletal actin was stained with AlexaFluor $488^{\circledR}$-Phalloidin (Invitrogen), cell nuclei with 4',6-diamidino-2-phenylindole (DAPI, Sigma). In the case of collagen-coated chitosan fibres, anti-bovine collagen type I (mouse IgG) (Sigma) was used to detect the collagen coating. AlexaFluor $546^{\circledR}$ conjugated goat antimouse IgG (Invitrogen) was used as the secondary antibody for staining. Acidic compartments were visualized by incorporation of 3-(2,4-dinitroanillino)-3'-amino-Nmethyldipropylamine (DAMP) into the cells using the acidic granule kit (Oxford Biomedical Research, UK) (Inoue et al., 1999). Therefore, cells were incubated with DAMP for $30 \mathrm{~min}$ before fixing. Incorporated DAMP was stained using anti-DNP (mouse $\mathrm{IgG}$ ) and counterstained with AlexaFluor $488^{\circledR}$ conjugated goat anti-mouse IgG (Invitrogen). Cathepsin K was labelled with anti-mouse cathepsin K (goat IgG) (Santa Cruz Biotechnology, Santa Cvruz, CA, USA), followed by staining with AlexaFluor $488^{\circledR}$ conjugated donkey anti-goat IgG (Invitrogen). In case of DAMP and Cathepsin K visualization the cytoskeletal actin was stained with AlexaFluor $546^{\circledR}$-Phalloidin. Activity of TRAP was detected using a modified ELF ${ }^{\circledR} 97$ Endogenous Phosphatase Detection method (Invitrogen) (Filgueira, 2004). This modified protocol uses the ELF ${ }^{\circledR} 97$ substrate in a slightly acid buffer and with the addition of tartrate. Additionally, cytoskeletal actin was stained with
AlexaFluor $488^{\circledR}$-Phalloidin. Microscopy was carried out on an upright Axioscop 2 FS mot equipped with a LSM 510 META module (Zeiss, Jena, Germany) controlling an argon-ion $\left(\mathrm{Ar}^{+}\right)$laser, helium-neon (HeNe) laser and NIRfemtosecond titanium-sapphire laser for 2-photon excitation (Coherent Mira 900F). Excitation of AlexaFluor $488^{\circledR}$ was carried out at $488 \mathrm{~nm}\left(\mathrm{Ar}^{+}\right.$laser $)$, the excitation of AlexaFluor $546^{\circledR}$ at $546 \mathrm{~nm}$ (HeNe laser). The NIR-fslaser was used for excitation of DAPI at $750 \mathrm{~nm}$ ( 2 photon excitation) and fluorescence was recorded at $461 \mathrm{~nm}$.

\section{Colorimetric measurements}

The Bone TRAP ELISA (Immunodiagnostic Systems, Frankfurt am Main, Germany) was used for biochemical analysis of osteclastic differentiation according to the manufacturer's instructions. The measurements were performed with cell lysates obtained after 18 days of cultivation. Cell lysis was achieved with $1 \%$ Triton $\mathrm{X}$ 100 (Sigma) in PBS for $60 \mathrm{~min}$. Ultrasonication (20 s, 80 W, UP 100H, Dr. Hielscher GmbH, Teltow, Germany) of the scaffolds was applied to support cell lysis. For the colorimetric measurements a SpectraFluor Plus microplate reader (Tecan, Crailsheim, Germany) was used.

\section{Statistics}

All measurements were carried out in triplicate and expressed as means \pm standard deviation.

\section{RT-PCR}

For analysis of gene expression by reverse transcriptionpolymerase chain reaction (RT-PCR), undifferentiated monocytes before seeding and differentiated monocytes 18 day after seeding on uncoated and collagen-coated fibre scaffolds were washed twice with PBS and immediately used for RNA preparation. Total RNA isolation was performed using the peqGOLD MicroSpin Total RNA Kit (Peqlab, Erlangen, Germany) according to the manufacturer's instructions. RNA concentration was measured using a Nanodrop ND 1000 (Peqlab). Complementary DNA (cDNA) was transcribed from 100 ng of total RNA in a $20 \mu \mathrm{L}$ reaction mix containing $200 \mathrm{U}$ of Superscript II Reverse Transcriptase (Invitrogen), 0.5 $\mathrm{mM}$ dNTP (Invitrogen), $12.5 \mathrm{ng} / \mu \mathrm{L}$ random hexamers (MWG Biotech, Ebersberg, Germany), and $40 \mathrm{U}$ of RNase inhibitor RNase OUT (Invitrogen). For cDNA synthesis, the reaction mixtures were incubated for $50 \mathrm{~min}$ at $42^{\circ} \mathrm{C}$ followed by $15 \mathrm{~min}$ at $70^{\circ} \mathrm{C}$ in a Thermocycler (Peqlab). For PCR experiments, $1 \mu \mathrm{L}$ of cDNA was used as template in a $20 \mu \mathrm{L}$ reaction mix containing specific primer pairs to detect transcripts of TRAP, cathepsin K (CatK), vitronectin receptor (VNR), calcitonin receptor $(\mathrm{CNR})$ and the housekeeping gene glyceraldehyde-3-phosphate dehydrogenase (GAPDH), respectively, for each sample. The primer sequences (MWG Biotech) and annealing temperatures are summarized in Table 1. After the initial activation step at $95^{\circ} \mathrm{C}$ for $4 \mathrm{~min}, 30 \mathrm{PCR}$ cycles were run with each a denaturation step at $95^{\circ} \mathrm{C}$ for $45 \mathrm{~s}$, an annealing step at $55^{\circ} \mathrm{C}$ or $57^{\circ} \mathrm{C}$ for $45 \mathrm{~s}$, and a synthesis step at $72^{\circ} \mathrm{C}$ for $1 \mathrm{~min}$ followed by a final synthesis step at $72^{\circ} \mathrm{C}$ for 10 min in a Primus 25 Advanced Thermocycler (Peqlab). The 
Table 1: Primers for RT-PCR

\begin{tabular}{|c|c|c|c|}
\hline Gene & Forward Primer & Reverse Primer & $\mathbf{T}_{\mathbf{A}}\left[{ }^{\circ} \mathbf{C}\right]$ \\
\hline GAPDH & 5' -GGTGAAGGTCGGAGTCAACGG-3' & 5' -GGTCATGAGTCCTTCCACGAT-3' & 55 \\
\hline TRAP & 5' -TTCTACCGCCTGCACTCCAA-3' & 5' - AGCTGATCTCCACATAGGCA -3' & 57 \\
\hline CatK & 5' -GATACTGGACACCCACTGGGA-3' & 5'-CATTCTCAGACACACAATCCAC-3' & 57 \\
\hline VNR & 5' -AAGTTGGGAGATTAGACAGAGG-3' & 5'-СТTTCTTGTTCTTGAGGTGG-3' & 57 \\
\hline CNR & 5' -CAATGCAACCTGGTCCAACT-3' & 5' -GCCTTCACAGCCTTCAGGTA-3' & 57 \\
\hline
\end{tabular}

same single stranded cDNA was used to investigate the expression of all genes described. The resulting PCRproducts were analyzed using the FlashGel ${ }^{\mathrm{TM}}$ Dock and documentation system (Cambrex Bio Science, East Rutherford, NJ, USA).

\section{Results}

Osteoclastogenesis of monocytes cultivated on uncoated and collagen-coated chitosan fibres was carried out using two scaffold models (Heinemann et al., 2008). The raw fibres show slightly edged cross-sections and diameters of about $20 \mu \mathrm{m}$ (Fig. 1a). Collagen coating results in the formation of smooth layers at the surface and inside the scaffold by spanning over several chitosan fibres (Fig. 1b). Supported chitosan scaffolds form a smooth surface of parallel-aligned fibres suitable for microscopic investigations (Fig. 1c). Stand-alone chitosan scaffolds made of the same material were used for biochemical assays and RT-PCR analysis (Fig. 1d).

\section{Microscopical studies on the differentiation of osteoclasts}

Osteoclast differentiation on the chitosan scaffolds was monitored by light microscopy, CLSM and SEM. The light microscopy images in Fig. 2 visualize the distribution of the cells attached to the uncoated chitosan fibres after 12 days of cultivation in osteoclast differentiation medium containing M-CSF and RANKL. The size of the cells varies from diameters of about $10 \mu \mathrm{m}$ to about $30-50 \mu \mathrm{m}$. Taking into account that cell size of monocytes is about $10 \mu \mathrm{m}$, formation of multinucleated osteoclast-like cells by fusion is obvious.

CLSM of the uncoated (Fig. 3a) and collagen-coated (Fig. 3c,e) chitosan scaffolds visualizes the blue fluorescent cell nuclei and green fluorescent actin skeletons which characterize the multinuclearity and the adaptation of the cells to the given substrate. Chitosan fibres are represented blue due to the autofluorescence signal. For the coated scaffolds collagen is visible as a red layer. Exactly the same samples were prepared for SEM investigations, to simultaneously visualize the morphology of the cells and the uncoated (Fig. 3b) or collagen-coated fibres (Fig. 3d,f).

For both scaffold types osteoclast-like cells have formed and are attached along the chitosan fibres after 12 days of cultivation. Considering the blue stained cell nuclei, it is clear to see that several nuclei share one actin skeleton. In case of collagen coating the osteoclast-like cells are also concentrated on the fibres but additionally spread in a lateral direction on the collagen layer. Especially Figure $3 \mathrm{e}$ highlights the preferred accumulation of osteoclast-like cells along one collagen-coated fibre and the presence of up to 5 nuclei within a single cell. To achieve better contrast, the red channel which represents the collagencoating was shielded in that case. Although remarkable adaption to the shape of the raw chitosan fibres is recognized, osteoclast-like cells occur larger and more spread on the collagen-coated scaffolds.

Corresponding SEM images confirm the CLSM results by showing adherent cells on the uncoated and coated chitosan fibres. However, cell patches are more difficult to identify on the coated scaffolds because cells and collagen exhibit a similar surface roughness. Spread
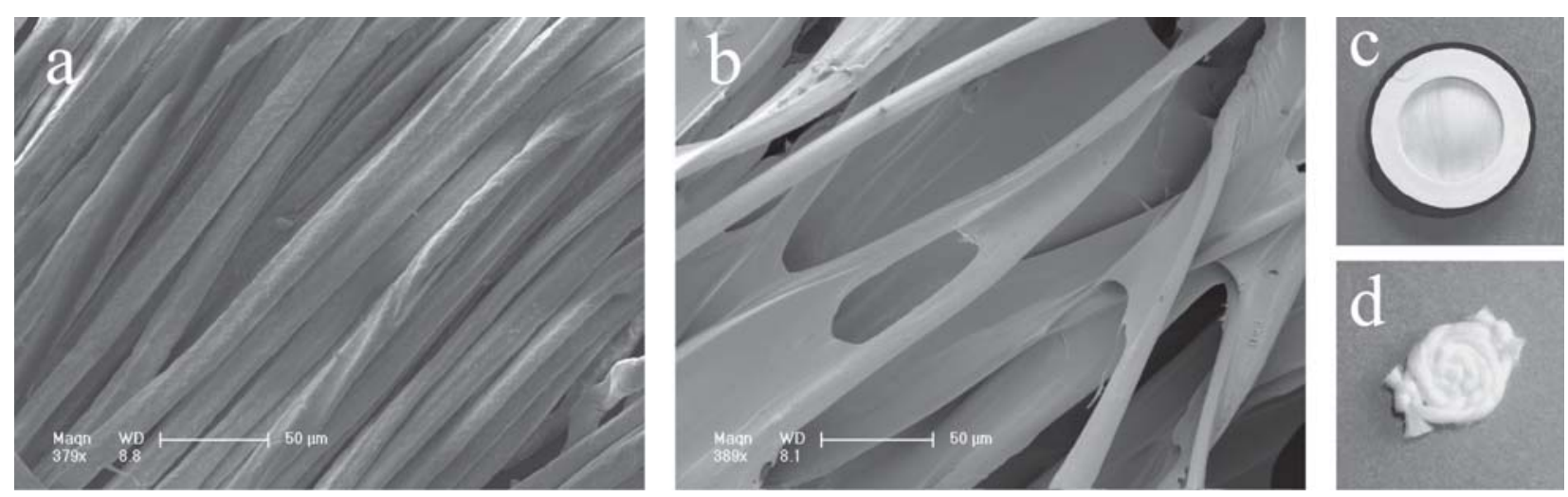

Fig. 1. SEM images of the uncoated (a) and collagen-coated (b) chitosan scaffolds. Photographs show the supported (c) and stand-alone (d) chitosan scaffolds prepared by the crown knot technique. 

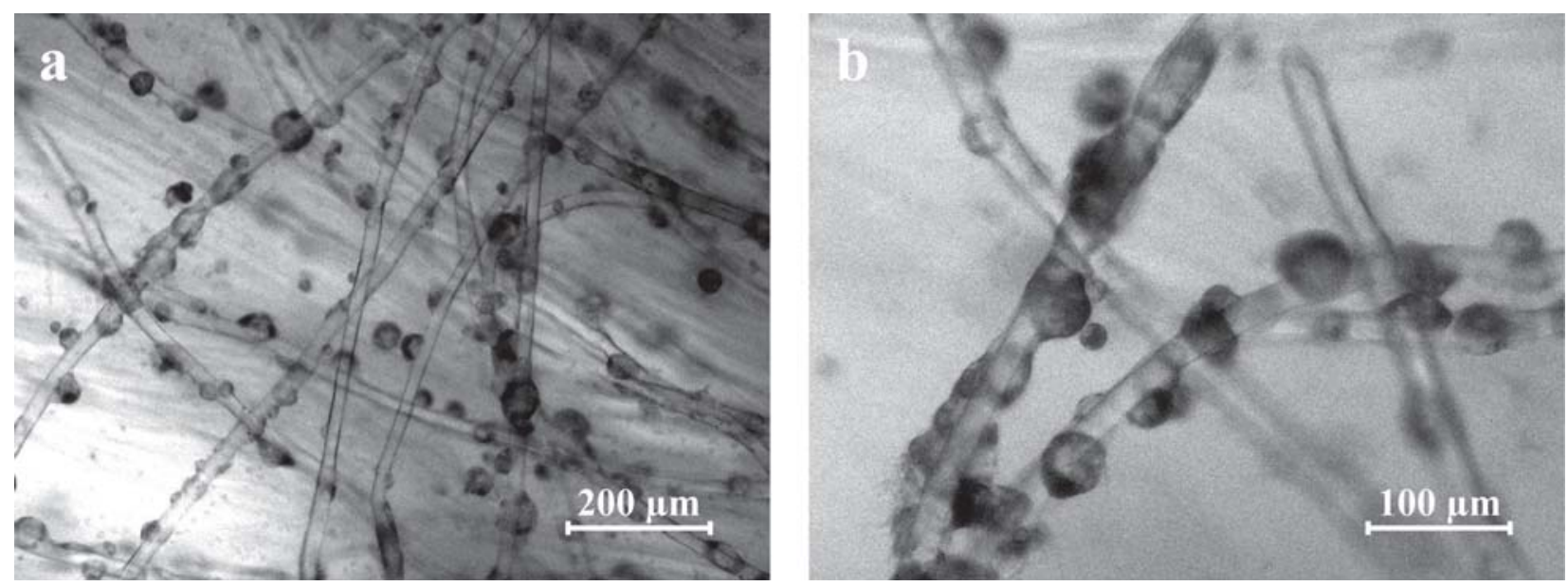

Fig. 2. Light microscopy image of osteoclast-like cells on uncoated chitosan fibers after 12 day of cultivation in osteoclast differentiation medium.

osteoclast-like cells are marked by black arrows and the still spherical monocytes by white arrows. The left white arrow in Fig. 3d marks two monocytes that just seem to be in an initial stadium to fuse. Fig. $3 \mathrm{f}$ is an enlarged image of Fig. 3d and shows the characteristic "ruffled border" of an osteoclast attached to a chitosan fibre.

After 18 days of culture, formation of acidic compartments of osteoclast-like cells was detected by incubation with DAMP followed by immunostaining and CLSM imaging. Fig. 4 shows cell nuclei (blue), actin skeletons (red) and acidic compartments (green) of osteoclast-like cells as well as the blue autofluorescence of the chitosan fibres. The overlap of red and green signals appears as yellow areas, which confirms acid compartments developed within all cells. Green areas without cells refer to acidic enrichments left behind by mobile osteoclast-like cells. Detection of acidic compartments on coated scaffolds is slightly disturbed by interference of red fluorescence of cell actin and collagen.

Differentiation of monocytes towards the osteoclastic lineage was additionally analyzed by microscopic detection of the typical markers cathepsin K and TRAP. Fig. 5a shows the cell nuclei (blue), actin skeletons (red) and cathepsin K (green) of osteoclast-like cells after 18 days of cultivation on the uncoated chitosan scaffold. The chitosan fibres occur as light blue in the image due to the autofluorescence. The green fluorescence confirms that cathepsin $\mathrm{K}$ is concentrated inside the cells. That is visible more clearly by shielding the red signal of the actin staining (inset of Fig. 5a). TRAP activity of osteoclast-like cells at the same time point is visualized as yellow dots in Fig. 5b. The actin skeleton is stained green. Detection of cathepsin $\mathrm{K}$ and TRAP on collagen-coated scaffolds is disturbed by autofluorescence of the scaffold.

\section{Biochemical studies on the differentiation of osteoclasts}

In addition to microscopical studies, enzymatic verification for osteoclastic differentiation of monocytes was carried out using the Bone TRAP ELISA, which is a specific method for the detection of the activity of tartrate-resistant acid phosphatase isoform $5 \mathrm{~b}$. Since TRAP $5 \mathrm{~b}$ is not expressed by monocytes but mature osteoclasts, the assay is intended for use as an indicator of bone resorption and osteoclastic differentiation. In vitro, TRAP $5 \mathrm{~b}$ activity reflects the number of osteoclasts and therefore the Bone TRAP ELISA can be conveniently used to determine osteoclast number in human osteoclast cultures (Alatalo et al., 2000; Rissanen et al., 2003).

After 18 days of culture distinct TRAP $5 \mathrm{~b}$ activity is detected for both scaffold types (Fig. 6). The absolute value for the collagen-coated scaffold is higher compared to that of the raw chitosan fibre scaffold.

\section{RT- PCR studies}

To further characterize the osteoclastic phenotype of the differentiated monocytes, gene expression of tartrate resistant acid phosphatase (TRAP), cathepsin K (CatK), vitronectin receptor (VNR), and calcitonin receptor (CNR) was analyzed after 18 days of culture on uncoated and collagen-coated fibre scaffolds. The results are compared to that of undifferentiated monocytes before seeding. Expression of the housekeeping gene glyceraldehyde-3phosphate-dehydrogenase (GAPDH) was determined to verify the usage of similar amounts of RNA for RT-PCR. Compared to the signals of undifferentiated monocytes, for all osteoclastic markers an increase of the transcript levels is detected for cells cultivated on uncoated and collagen-coated fibre scaffolds after 18 days (Fig. 7). That indicates the differentiation to osteoclasts on both scaffold modifications. Gene expression levels are slightly higher for the collagen-coated fibre scaffolds.

\section{Discussion}

The evaluation of new bone graft materials initially focuses on the response to osteoblasts and their precursors to the respective material, by analyzing biocompatibility, osteoconductivity or osteoinductivity. However, the success of an implant not only depends on the interaction with osteoblasts. Osteoblasts are responsible for the generation of bone extracellular matrix but also regulate the differentiation and activity of osteoclasts. The 

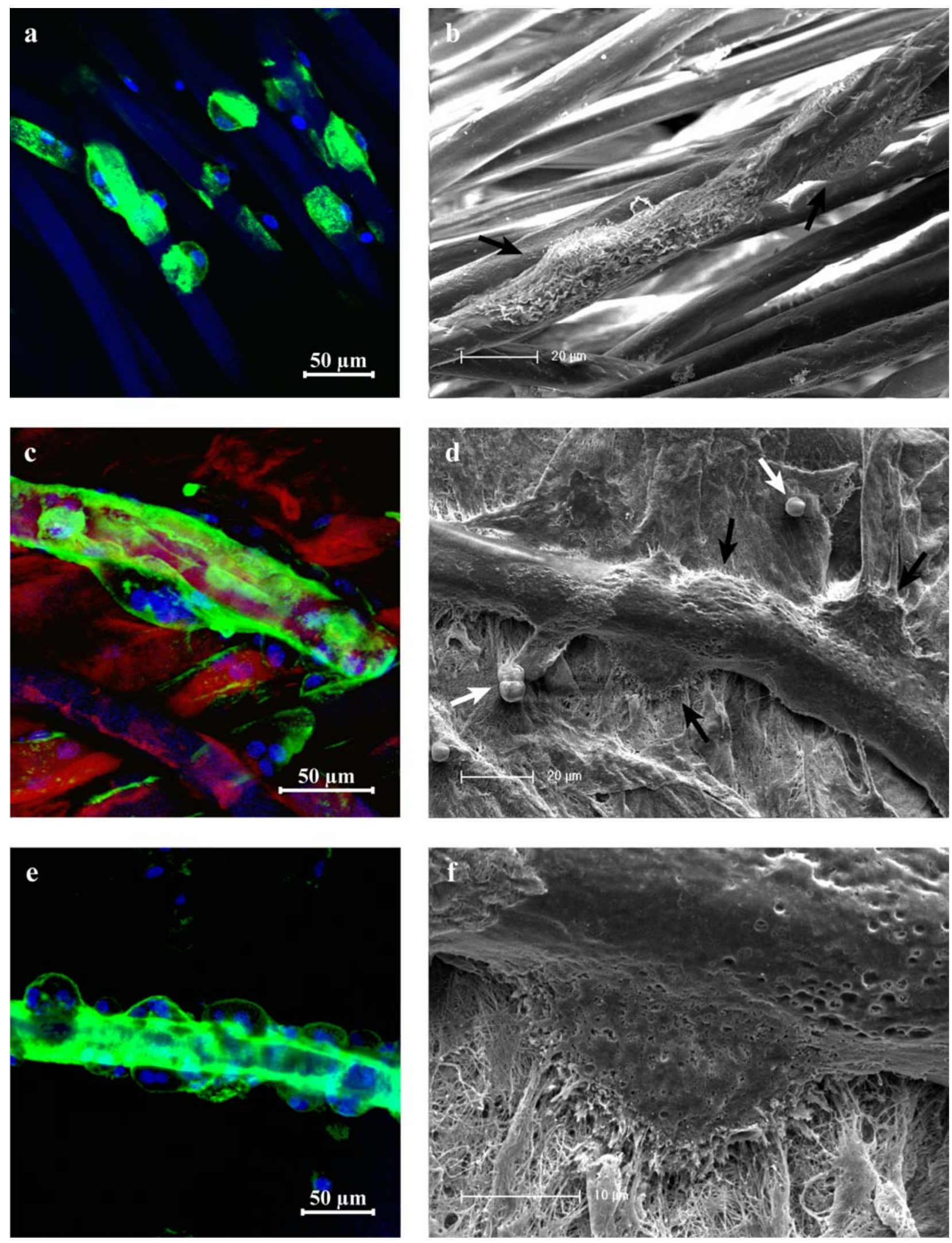

Fig. 3. 3D reconstructions from CLSM image stacks (left column) and SEM images (right column) of monocytederived osteoclast-like cells after 12 days of cultivation on uncoated $(a, b)$ as well as collagen-coated (c-f) chitosan scaffolds. The actin skeletons (green), the nuclei (blue), and the collagen-coating (red) are visible. In panel e the red channel is shielded for better visibility. White arrows in the SEM images point to monocytes and the black arrows point to osteoclast-like cells. 

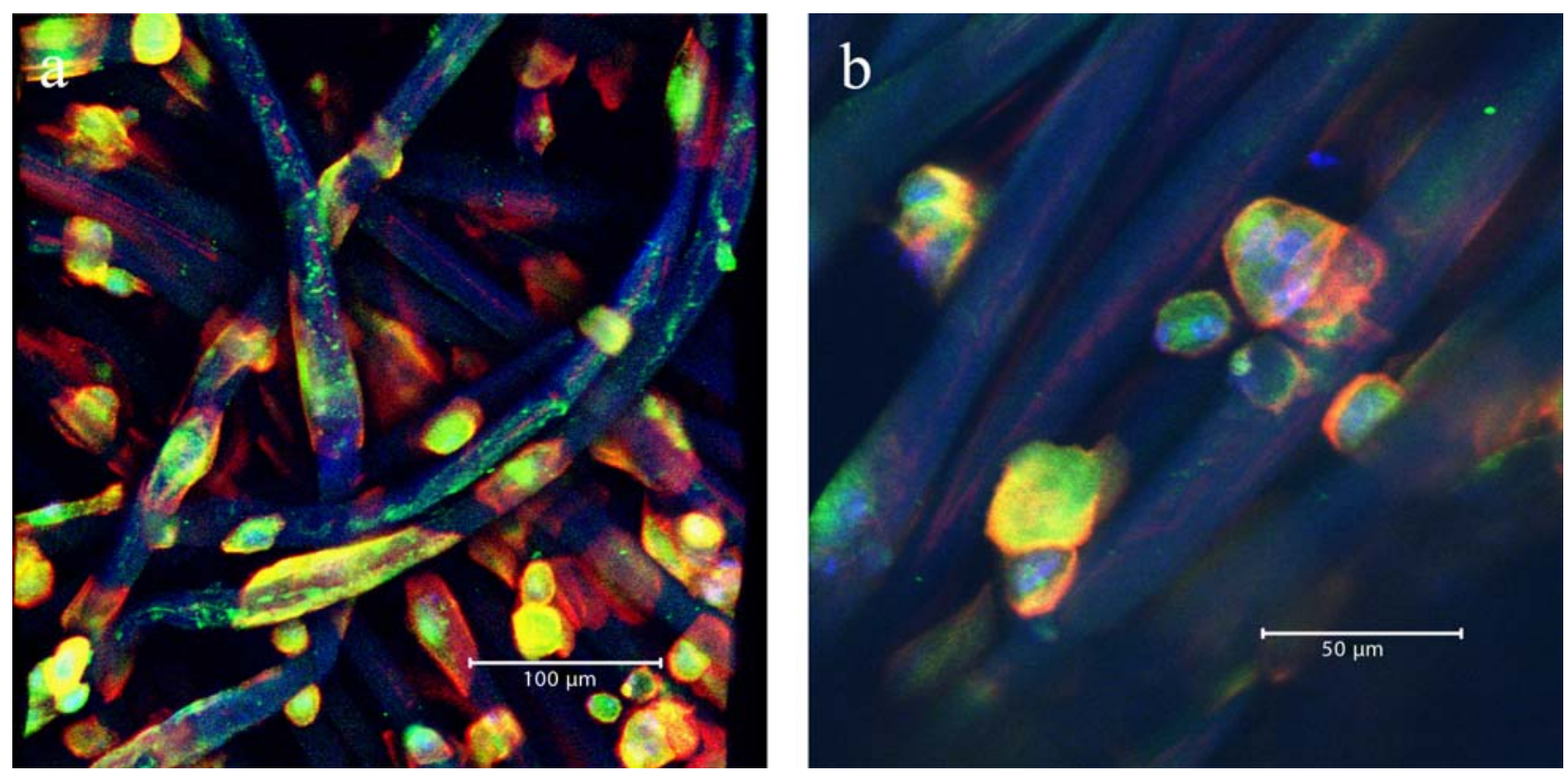

Fig. 4. 3D reconstructions from CLSM image stacks of monocyte-derived osteoclast-like cells after 18 days of cultivation on uncoated chitosan scaffolds. DAMP visualization of the acidic compartments (green), actin (red) and the nuclei (blue).
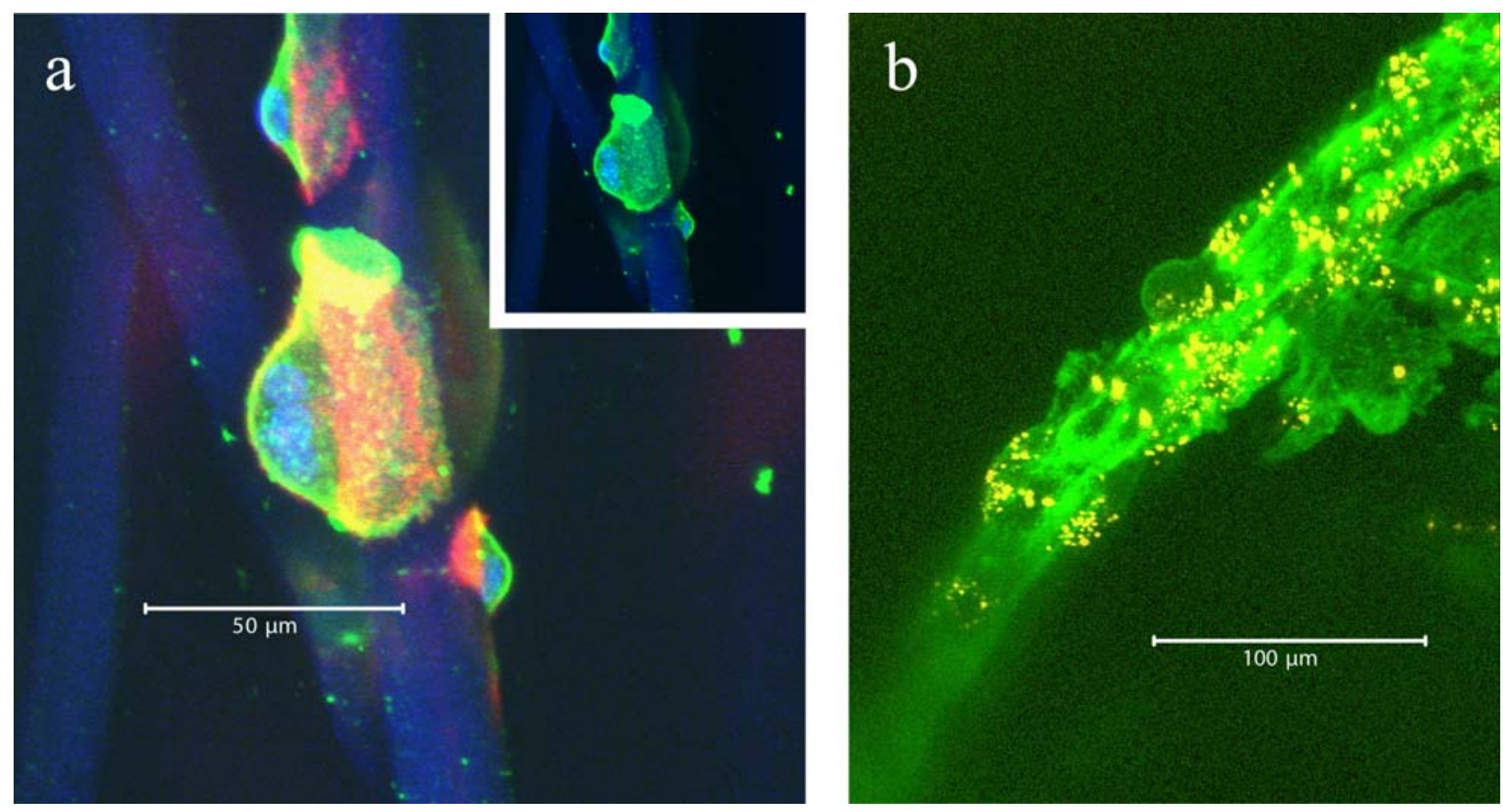

Fig. 5. 3D reconstructions from CLSM image stacks of monocyte-derived osteoclast-like cells after 18 days of cultivation on chitosan scaffolds. Image (a) shows cathepsin K (green) in osteoclast-like cells on uncoated chitosan fibres. The actin skeletons are stained red and the nuclei blue. Image (b) shows TRAP activity (yellow dots) of the cells (actin skeletons are stained green) on uncoated chitosan fibres.

coordinated action of osteoblasts and osteoclasts is critical for bone remodelling. Therefore the investigation of osteoclast differentiation and function on a new biomaterial is of great interest. Osteoclastic resorption may affect bone formation and is a crucial step for the conversion of the bone graft material into native bone. A fast remodelling process of the bone graft is desirable and strongly depends on the conductivity of the material to both osteoblasts and osteoclasts. Textile chitosan scaffolds, applied in the present study were already extensively analyzed with respect to their interaction with osteoblasts as well as osteoprogenitor cells (Heinemann et al., 2008; Heinemann et al., 2009). Consequently, the differentiation of human monocytes into osteoclasts cultivated on the chitosan scaffolds was investigated and is reported. All cell culture experiments were performed for the uncoated and for the collagen-coated chitosan scaffolds in order to evaluate the biocompatibility.

There are few reports on the successful formation of osteoclasts on porous bone graft materials in vitro. Perotti 


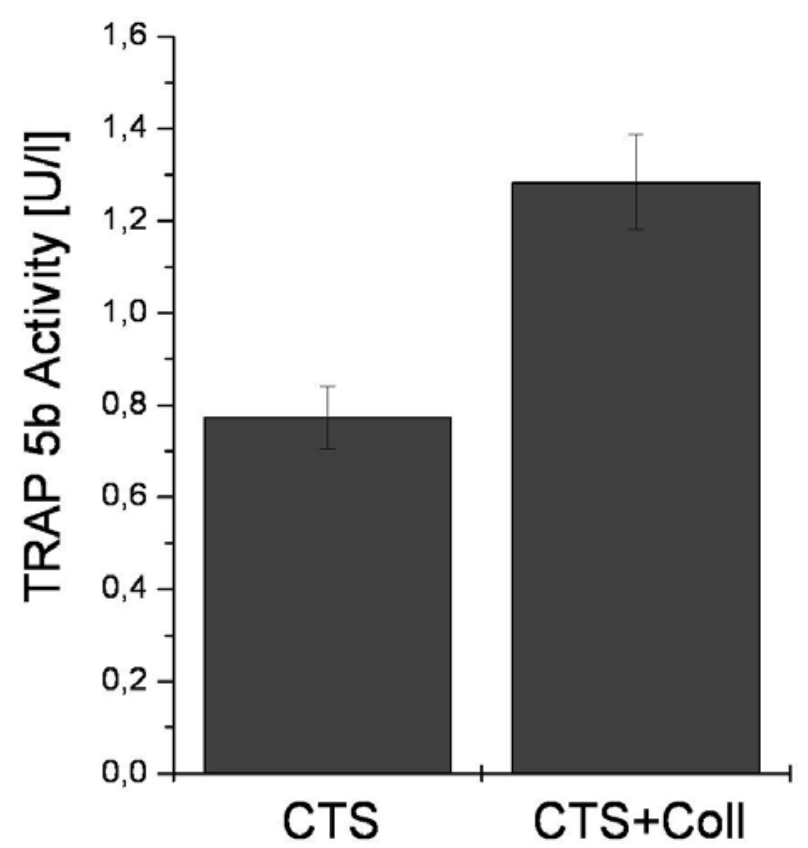

Fig. 6. TRAP $5 \mathrm{~b}$ activity of induced monocytes after 18 days of cultivation on uncoated (CTS) and collagen-coated (CTS+Coll) chitosan fibre scaffolds.

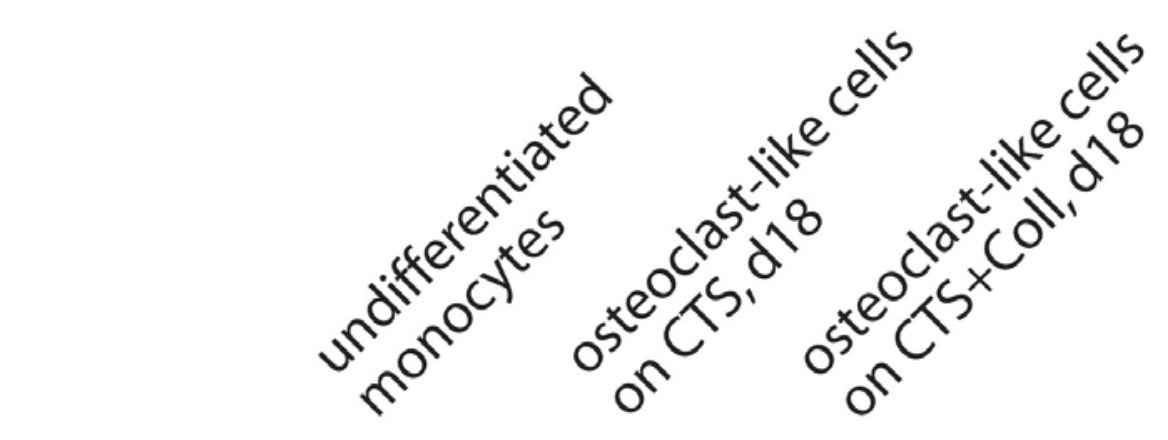

GAPDH

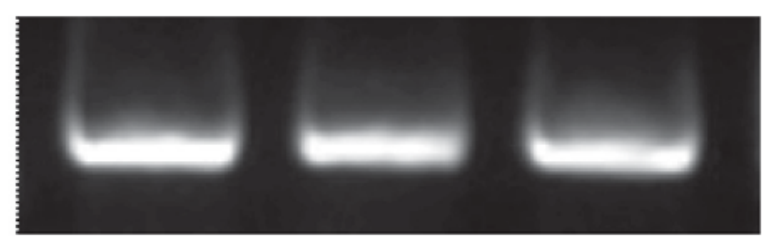

TRAP

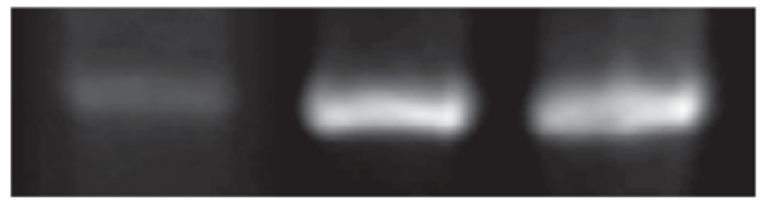

CatK

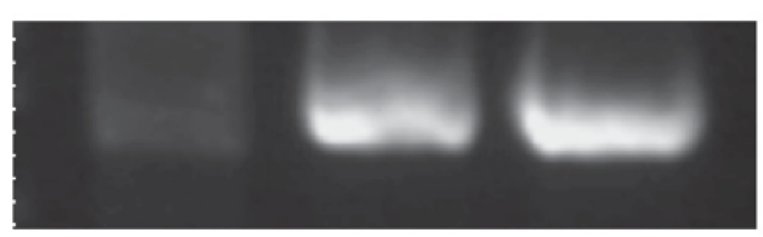

VNR

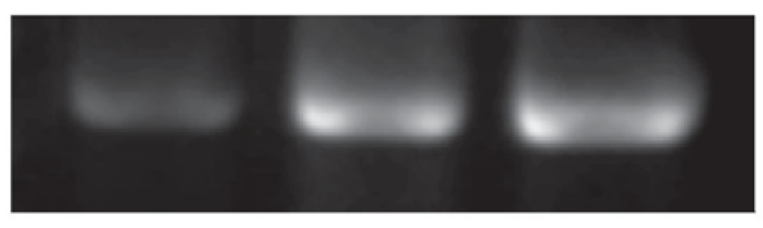

CNR

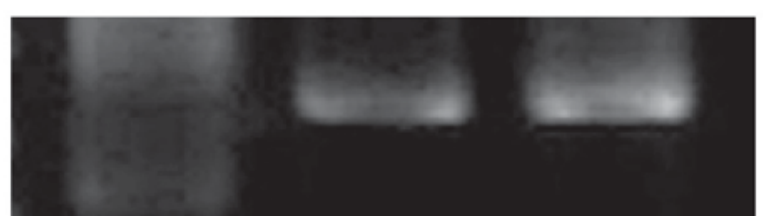

Fig. 7. RT-PCR expression analysis of induced monocytes after 18 days of cultivation on uncoated (CTS) and collagen-coated (CTS + Coll) chitosan fibre scaffolds in comparison to undifferentiated monocytes. 
and co-workers succeeded in differentiating osteoclast-like cells from peripheral blood mononuclear cells on a xenogenous bone grafting material of equine origin (Perrotti et al., 2009). However these authors also report a discontinuity of the resorption pattern, which might be caused by the complex three-dimensional structure of the material. The differentiation of murine osteoclast precursors in a porous silicon-stabilized ceramic was investigated by Tortelli et al. in co-culture using murine osteoblasts (Tortelli et al., 2009). Gene expression of osteoclastic markers TRAP and cathepsin K was lower for cells cultured in the porous ceramic compared to the control on polystyrene surfaces. Differentiation of osteoclast precursors from minipig in mineralized resorbable polymer foam was achieved by Nakagawa and co-workers (Nakagawa et al., 2004). Formation of osteoclast-like cells was confirmed by microscopic investigations.

Important requirements for monocytes to form multinuclear osteoclast-like cells are biocompatibility of the material, sufficient cell density, and especially the possibility for the cells to migrate on the substrate with the aim to fuse. That ability is mainly determined by the substrate morphology, which is confirmed in the present study. Flat two-dimensional surfaces enable free lateral movement of the cells resulting in extensive colonies and the formation of large multinuclear osteoclast-like cells.

In contrast, the raw textile chitosan scaffold specifies one-dimensional pathways along the fibres, which limits cell movement to two directions. Conditions change due to the presence of collagen layers formed during the coating process. These layers provide additional areas for the monocytes to adhere and migrate to become fused. The influence of the initial situation is confirmed by the microscopical investigations. After 12 days of cultivation adherent multinuclear cells were recognized on both scaffold types. However, CLSM suggests that more nuclei (each representing one initial monocyte cell) have fused to become one osteoclast-like cell, when cultivated on the collagen-coated scaffolds. Also cell spreading is clearer for the coated samples. This is in accordance to the quantitative determination of TRAP 5b activity (Fig. 6), which was higher for osteoclasts on collagen-coated samples compared to osteoclasts on uncoated chitosan scaffolds. In a recently published study, chitosan fibres were incorporated into calcium phosphate cement (Rochet et al., 2009). Differentiation of human preosteoclasts into osteoclasts was significantly lower compared to the pure cement and only few TRAP-positive multinuclear cells were found on the cement/chitosan composite. Possibly, there is a negligible inhibiting effect of chitosan on osteoclastogenesis in our study too, which would explain the higher number of osteoclasts on collagen-coated chitosan scaffolds. On the other hand, the conditions for the formation of multinuclear osteoclast-like cells might be better on the collagen-coated samples due to their more favourable surface morphology.

The combination of CLSM and SEM is particularly suitable to simultaneously visualize the morphology, distribution, orientation of the cells, and the topography of the uncoated and collagen-coated scaffolds. Once again, the presence of spherical monocytes and the affinity of the giant osteoclast-like cells to the chitosan fibres are recorded. The magnification of the osteoclast-like cells reveals the spreading towards the collagen layer and the formation of the typical "ruffled border". The presence of that outer membrane characterizes the transition of an osteoclast to the resorption stage, which can result in disintegration of extracellular matrix, e.g. collagen (Ren et al., 2005). That process is also visible as irregular arranged collagen fibrils of the coating near the osteoclast.

Furthermore, the differentiation of the monocytes into osteoclasts is demonstrated by CLSM detection of the three typical markers DAMP, cathepsin K and TRAP. DAMP is a marker for low $\mathrm{pH}$ in order to examine acidic compartments of osteoclasts cultured on the chitosan scaffolds. Immunofluorescence was localized predominantly on the substratum side of actively resorbing osteoclasts, whereas an evenly distributed staining pattern was seen in the nonactive cell. The distribution pattern of DAMP seemed to be correlated with the osteoclastic activity, since osteoclasts exhibit alternating resorption and migration phases during the bone remodelling cycle.

Cathepsin $\mathrm{K}$ is a collagenolytic, papain-like, cysteine protease that is mainly expressed in osteoclasts, and is secreted into the resorptive pit. In the osteoclast, cathepsin $\mathrm{K}$ functions in the resorptive process. Upon polarization of the osteoclast over the site of resorption, cathepsin $\mathrm{K}$ is secreted from the ruffled border into the resorptive pit. Here, it is the major protease involved in the degradation of collagen type I and other noncollagenous proteins, which have been demineralised by the acidic environment of the resorptive pit.

The differentiation of the monocytes into osteoclastlike cells is further confirmed by microscopic investigations and an immunoassay of TRAP activity. Two isoforms of TRAP circulate in human blood, known as TRAP 5a and TRAP 5b. Only TRAP 5b isoform is derived from osteoclasts (Halleen et al., 2000; Halleen et al., 2002; Yam and Janckila, 2003). Since these isoforms derive from post-translational processing of a common gene product, gene expression analyses are not sufficient to distinguish between the isoforms. Therefore we additionally performed an immunoassay for TRAP 5b, which clearly showed the presence of TRAP $5 b$ in our cell cultures on raw and collagen-coated chitosan.

\section{Conclusion}

The ability of textile chitosan fibre scaffolds to support the adhesion and migration of human monocytes, followed by fusion to form multinuclear osteoclast-like cells is demonstrated in the study. The in vitro experiments suggest that optional coating with collagen can be applied to improve the monocyte migration and fusion process. The procedure also enhances the presence or activity of typical osteoclastic markers compared to cell cultivation on raw chitosan. For both scaffold types, the requirements to enable desirable cell-induced scaffold material resorption, which is an important basis for the inclusion of material in the remodelling process, are completed. 


\section{References}

Alatalo SL, Halleen JM, Hentunen TA, Monkkonen J, Vaananen HK (2000) Rapid screening method for osteoclast differentiation in vitro that measures tartrateresistant acid phosphatase $5 \mathrm{~b}$ activity secreted into the culture medium: Clin Chem 46: 1751-1754.

Athanasiou KA, Niederauer GG, Agrawal CM (1996) Sterilization, toxicity, biocompatibility and clinical applications of polylactic acid/polyglycolic acid copolymers: Biomaterials 17: 93-102.

Chen CL, Wang YM, Liu CF, Wang JY (2008) The effect of water-soluble chitosan on macrophage activation and the attenuation of mite allergen-induced airway inflammation: Biomaterials 29: 2173-2182.

Cunha-Reis C, Tuzlakoglu K, Baas E, Yang Y, El Haj A, Reis RL (2007) Influence of porosity and fibre diameter on the degradation of chitosan fibre-mesh scaffolds and cell adhesion: J Mater Sci Mater Med 18: 195-200.

Detsch R, Mayr H, Ziegler G (2008) Formation of osteoclast-like cells on HA and TCP ceramics: Acta Biomater 4: 139-148.

Di Martino A, Sittinger M, Risbud MV (2005) Chitosan: a versatile biopolymer for orthopaedic tissueengineering: Biomaterials 26: 5983-90.

Domaschke H, Gelinsky M, Burmeister B, Fleig R, Hanke T, Reinstorf A, Pompe W, Rosen-Wolff A (2006) In vitro ossification and remodeling of mineralized collagen I scaffolds: Tissue Eng 12: 949-958.

Filgueira L (2004) Fluorescence-based staining for tartrate-resistant acidic phosphatase (TRAP) in osteoclasts combined with other fluorescent dyes and protocols: J Histochem Cytochem 52: 411-414.

Halleen JM, Alatalo SL, Suominen H, Cheng S, Janckila AJ, Vaananen HK (2000) Tartrate-resistant acid phosphatase 5b: a novel serum marker of bone resorption: J Bone Miner Res 15: 1337-1345.

Halleen JM, Ylipahkala H, Alatalo SL, Janckila AJ, Heikkinen JE, Suominen H, Cheng S, Vaananen HK (2002) Serum tartrate-resistant acid phosphatase $5 \mathrm{~b}$, but not $5 \mathrm{a}$, correlates with other markers of bone turnover and bone mineral density: Calcif Tissue Int 71: 20-25.

Heinemann C, Heinemann S, Bernhardt A, Worch H, Hanke T (2008) Novel textile chitosan scaffolds promote spreading, proliferation, and differentiation of osteoblasts: Biomacromolecules 9: 2913-2920.

Heinemann C, Heinemann S, Lode A, Bernhardt A, Worch H, Hanke T (2009) In vitro evaluation of textile chitosan scaffolds for tissue engineering using human bone marrow stromal cells: Biomacromolecules 10: 1305-1310.

Hench LL, Polak JM (2002) Third-generation biomedical materials: Science 295: 1014-1017.

Hsu SH, Whu SW, Hsieh SC, Tsai CL, Chen DC, Tan TS (2004) Evaluation of chitosan-alginate-hyaluronate complexes modified by an RGD-containing protein as tissue-engineering scaffolds for cartilage regeneration: Artif Organs 28: 693-703.

Huang M, Vitharana SN, Peek LJ, Coop T, Berkland C (2007) Polyelectrolyte complexes stabilize and controllably release vascular endothelial growth factor: Biomacromolecules 8: 1607-1614.
Inoue M, Yoshida H, Akisaka T (1999) Visualization of acidic compartments in cultured osteoclasts by use of an acidotrophic amine as a marker for low $\mathrm{pH}$. Cell Tissue Res 298: 527-537.

Jayakumar R, Selvamurugan N, Nair SV, Tokura S, Tamura H (2008) Preparative methods of phosphorylated chitin and chitosan - an overview: Int J Biol Macromol 43: 221-5.

Jones GL, Motta A, Marshall MJ, El Haj AJ, and Cartmell SH (2009) Osteoblast: osteoclast co-cultures on silk fibroin, chitosan and PLLA films: Biomaterials 30: 5376-84.

Khor E, Lim LY (2003) Implantable applications of chitin and chitosan: Biomaterials 24: 2339-2349.

Kim IY, Seo SJ, Moon HS, Yoo MK, Park IY, Kim BC, Cho CS (2008) Chitosan and its derivatives for tissue engineering applications: Biotechnol Adv 26: 1-21.

Kohn P, Winzler J, Hoffman RC (1962) Metabolism of D-glucosamine and N-acetyl-D-glucosamine in the intact rat: J Biol Chem 237: 304-308.

Kumar MN, Muzzarelli RA, Muzzarelli C, Sashiwa H, Domb AJ (2004) Chitosan chemistry and pharmaceutical perspectives: Chem Rev 104: 6017-6084.

Manjubala I, Ponomarev I, Wilke I, Jandt KD (2008) Growth of osteoblast-like cells on biomimetic apatitecoated chitosan scaffolds: J Biomed Mater Res B Appl Biomater 84: 7-16.

Muzzarelli RA, Mattioli-Belmonte M, Tietz C, Biagini R, Ferioli G, Brunelli MA, Fini M, Giardino R, Ilari P, Biagini G (1994) Stimulatory effect on bone formation exerted by a modified chitosan: Biomaterials 15: 10751081.

Nakagawa K, Abukawa H, Shin MY, Terai H, Troulis MJ, Vacanti JP (2004) Osteoclastogenesis on tissueengineered bone: Tissue Eng 10: 93-100.

Niekraszewicz A, Kucharska M, Wawro D, Struszcyk M, Kopias K, Rogaczewska A (2007) Fibers and Textiles in Eastern Europe 15: 105-9.

Ohkawa K, Cha D, Kim H, Nishida A, Yamamoto H (2004) Electrospinning of Chitosan: Macromol Rapid Commun 25: 1600-1605.

Park YJ, Kim KH, Lee JY, Ku Y, Lee SJ, Min BM, Chung CP (2006) Immobilization of bone morphogenetic protein-2 on a nanofibrous chitosan membrane for enhanced guided bone regeneration: Biotechnol Appl Biochem 43: 17-24.

Perrotti V, Nicholls BM, Piattelli A (2009) Human osteoclast formation and activity on an equine spongy bone substitute: Clin Oral Implants Res 20: 17-23.

Ren S, Takano H, Abe K (2005) Two types of bone resorption lacunae in the mouse parietal bones as revealed by scanning electron microscopy and histochemistry: Arch Histol Cytol 68: 103-113.

Rissanen JP, Hentunen TA, Halleen JM (2003) Development and characterization of a novel human in vitro bone resorption assay useful for preclinical testing of drug candidates: J Bone Miner Res 18: SA256.

Rochet N, Balaguer T, Boukhechba F, Laugier JP, Quincey D, Goncalves S, Carle GF (2009) Differentiation and activity of human preosteoclasts on chitosan enriched calcium phosphate cement: Biomaterials 30: 4260-4267. 
Salgado AJ, Coutinho OP, Reis RL (2004) Bone tissue engineering: state of the art and future trends: Macromol Biosci 4: 743-765.

Schilling AF, Filke S, Brink S, Korbmacher H, Amling M, Rueger JM (2006) Osteoclasts and Biomaterials: Eur J Trauma 32: 107-113.

Schilling AF, Linhart W, Filke S, Gebauer M, Schinke T, Rueger JM, Amling M (2004) Resorbability of bone substitute biomaterials by human osteoclasts: Biomaterials 25: 3963-72.

Shi C, Zhu Y, Ran X, Wang M, Su Y, Cheng T (2006) Therapeutic potential of chitosan and its derivatives in regenerative medicine: J Surg Res 133: 185-192.

Slavik GJ, Ragetly G, Ganesh N, Griffon DJ, Cunningham BT (2007) A replica molding technique for producing fibrous chitosan scaffolds for cartilage engineering: J Mater Chem 17: 4095-4101.

Suda T, Udagawa N, Nakamura I, Miyaura C, Takahashi N (1995) Modulation of osteoclast differentiation by local factors: Bone 17: 87S-91S.

Taylor MS, Daniels AU, Andriano KP, Heller J (1994) Six bioabsorbable polymers: in vitro acute toxicity of accumulated degradation products: J Appl Biomater 5: 151157.

Tortelli F, Pujic N, Liu Y, Laroche N, Vico L, Cancedda $\mathrm{R}$ (2009) Osteoblast and osteoclast differentiation in an in vitro three-dimensional model of bone: Tissue Eng Part A.

Tuzlakoglu K, Alves CM, Mano JF, Reis RL (2004) Production and characterization of chitosan fibers and 3D fiber mesh scaffolds for tissue engineering applications: Macromol Biosci 4: 811-819.

Tuzlakoglu K, and Reis RL (2007) Formation of bonelike apatite layer on chitosan fiber mesh scaffolds by a biomimetic spraying process: J Mater Sci Mater Med 18: 1279-86.

Uragami T, and Tokura S, 2006, Enzymes involved in chitin and chitosan decomposition and synthesis, material science of chitin and chitosan, Springer Verlag, p. 81-112.

Wang J, Chen Y, Ding Y, Shi G, and Wan C (2008) Research of the degradation products of chitosan's angiogenic function: Appl. Surf. Sci. 255: 260-2.

Wawro D, Ciechañska D, Stêplewski W, and Bodek A (2006) Fibres \& Textiles in Eastern Europe 14: 97-101. Yam LT, and Janckila AJ (2003) Tartrate-resistant acid phosphatase (TRACP): a personal perspective: J Bone Miner Res 18: 1894-6.

Zisch AH, Lutolf MP, and Hubbell JA (2003) Biopolymeric delivery matrices for angiogenic growth factors: Cardiovasc Pathol 12: 295-310. 